\title{
Accuracy of GPS Positioning in the Presence of Large Height Differences
}

\author{
D. Ugur SANLI and Fatih KURUMAHMUT, Turkey
}

Key words: GPS baseline accuracy, continuous GPS applications, GPS positional time dependency accuracy

\section{SUMMARY}

Predicting the accuracy of GPS positioning is of great interest to researchers recently. Today, empirical formulas that predict GPS accuracies from local to regional scales are available for the scientific and surveying communities. Hence it is a useful survey planning tool prior to field works for various geodetic applications. Research results on this matter indicate that GPS positioning accuracies are the function of observing session duration over local to medium scales whereas the accuracies are the function of both observing session duration and inter-station distance over regional scales. In this study, we would like to introduce a new constraint, i.e. the inter-station height difference that needs to be taken into account in GPS positioning accuracy studies. This effect was first brought to the mind in the late 1980s indicating that GPS vertical positioning accuracy is degraded due to large height difference between baseline points. The prime factor degrading the GPS positioning accuracies is the fact that instant meteorological conditions are not taken into consideration when applying troposphere zenith delay corrections (i.e. the relative troposphere is not estimated between baseline points). Today, correction models that eliminate anomalous troposphere effects from vertical positioning solutions are available, and the results are well documented for various engineering applications such as monitoring of dams, tall buildings, landslides, and etc. However the effect has not been taken into consideration for positioning accuracy studies yet. Here we first study the effect over the Southern California Integrated GPS Network (SCIGN) using about 25 GPS baselines and NASA's GIPSY OASIS II research software. Then we model height dependent variation using Least Squares analysis. We show how the effect varies with respect to the observing session duration and the GPS baseline components north, east and up.

TS 3H - Reliability of Positioning and Measurement Technology 


\title{
Accuracy of GPS Positioning in the Presence of Large Height Differences
}

\author{
D. Ugur SANLI and Fatih KURUMAHMUT, Turkey
}

\section{INTRODUCTION}

Early trials to show the effect of large height difference on positioning accuracy date back to late 1980s. Gurtner et al. (1989) revealed that the accuracy of GPS vertical positioning decreases in mountainous areas when using only a standard troposphere model to eliminate troposphere based errors. On the other hand, the accuracy is improved if a relative residual troposphere bias is estimated along with the other positional parameters. At that time, continuous GPS monitoring was not as common as these days therefore the results were usually peculiar to campaign/episodic measurements (i.e. measurements that were collected every now and then with a few hours).

Not much has been done on this issue since then because today troposphere induced biases could be eliminated with sophisticated troposphere estimation models using new generation mapping functions and continuous (24 h) GPS data (Blewitt 1993, Boehm et al. 2006, Niell 1996). Recently Schon (2007) proposed a correction model for local GPS networks with large height differences for monitoring of land slides. Results of $48 \mathrm{~h}$ solutions were taken as basis for the corrections of the solutions from 8 h GPS campaigns. Sanli et al. (2005) showed that troposphere related effects show different behaviours with respect to (1) inter-station baseline length (2) inter-station height difference. They revealed that height difference dependent errors grow more rapidly (i.e. at a higher rate) as opposed to the distant dependent errors. Sanli et al. (2005) also studied the effect of large height difference on GPS commercial software results. They compare their findings with research software solutions. Commercial software results show large scatter values reaching up to a few centimetres although $24 \mathrm{~h}$ GPS data are used. This is due to the fact that some commercial software still uses only a standard troposphere model to eliminate troposphere induced errors. In addition, even if a relative troposphere bias is estimated in most of the commercial software today, absolute value of tropospheric zenith delays is not properly known (Kouba 2005). Also sophisticated mapping functions are not usually used with commercial software (Boehm et al. 2006). Research software results are only degraded when observing session duration is kept shorter than $24 \mathrm{~h}$ (Sanli 2006, Sanli and Kurumahmut 2007).

In this study, we perform a detailed study on how the accuracy of GPS positioning varies with respect to observing session duration in the presence of large height differences. We carry out our experiments over a densified sample, using 26 baselines in almost equal lengths incrementing only the height difference between baseline points starting from $50 \mathrm{~m}$ up to $1500 \mathrm{~m}$. It is useful to know accuracies in this sense because many engineering applications involving large height difference such as monitoring of bridges, tall buildings, landslides and dams today still require the use of campaign/episodic GPS as far as the economy is concerned (Brunner 2005, Lovse et al. 1995, Schon 2007).

TS 3H - Reliability of Positioning and Measurement Technology 


\section{STUDY AREA AND GPS DATA ANALYSIS}

GPS data were obtained from the SOPAC archives at http://sopac.ucsd.edu/. A total of 47 permanent GPS sites distributed widely across California, US were selected to form 26 baselines the lengths of which varying between 10 and $15 \mathrm{~km}$. Locations of the permanent GPS stations used throughout the study are shown in Figure 1.

GPS data was obtained in Receiver Independent Exchange (RINEX) format and sampled with 15 degree elevation cut off angle and 30 second recording intervals. JPL final precise orbits and clocks were used in the analysis. Jet Propulsion Laboratory's GIPSY/OASIS II software was used to process the GPS data, applying the "precise point positioning" method (PPP) by Zumberge et al. (1997). Then PPP results were differenced to obtain results equivalent to conventional relative positioning.

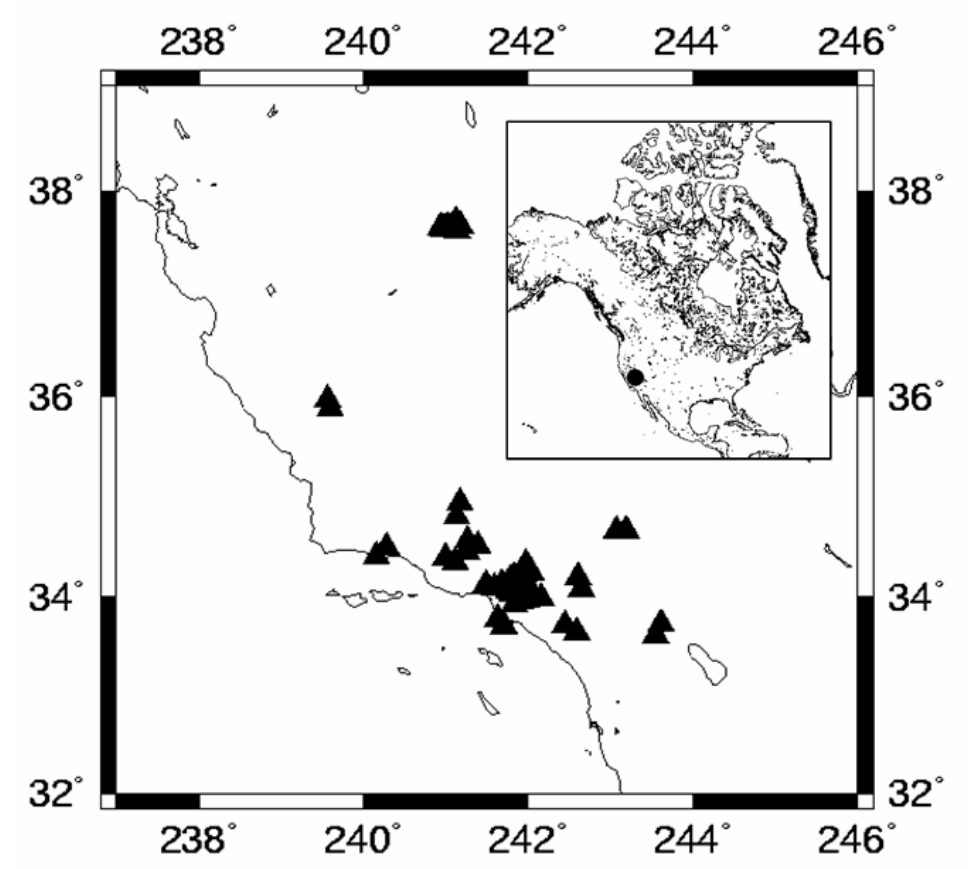

Fig. 1. Distribution of permanent GPS stations used in the study

For each baseline, we selected 10 days of data observed in May and June 2003 (GPS days 150 through 159). Each day's data were subdivided into mutually non-overlapping sessions for each of several selected values of the observing session $T$ (1, 2, 3, 4, 6, 8, 12 and $24 \mathrm{~h}$ ). For each subset of data, we computed the positional coordinates using the PPP method described above. For each day and each unknown point, a position was computed for each $24 \mathrm{~h}$ session. The average position from the ten $24 \mathrm{~h}$ sessions was then adopted as the 'true' position of the point. For each baseline, the differences in north, east and up (n, e, and u) from this true position were determined for every observing session as described in Soler et al. (2005) but using GIPSY utilities. These differences form the basis for the statistics presented throughout this paper. RMS values in each component were then computed for each baseline and each value of $T$. Any individual component of a positional difference that exceeded its

TS 3H - Reliability of Positioning and Measurement Technology

D. Ugur Sanli and Fatih Kurumahmut

Accuracy of GPS Positioning in the Presence of Large Height Differences

Integrating Generations

FIG Working Week 2008

Stockholm, Sweden 14-19 June 2008 
corresponding RMS value by more than a factor of three was then discarded as an outlier and the corresponding RMS value was recomputed.

\section{ACCURACY VARIATION WITH RESPECT TO OBSERVING SESSION DURATION AND HEIGHT DIFFERENCE}

In this section, we investigate how accuracy varies with respect observing session duration and height difference. For simplicity, only 1 to $3 \mathrm{~h}$ analyses are represented in Figure 2. Also note the scale difference for the vertical axis between horizontal and vertical components. It is clear from the figure that as height differences between baseline points grow, RMS values of positioning solutions from short sessions become larger. In addition, accuracy of GPS baseline components are improved as the session length grows. Linear association exists between the solution RMS and all three GPS baseline components (i.e., n, e, and u). Significance of this association has statistically been tested and proved for 95\% confidence levels. This linear association was previously mentioned by Gurtner et al. (1989) and Schon (2007).

1-h
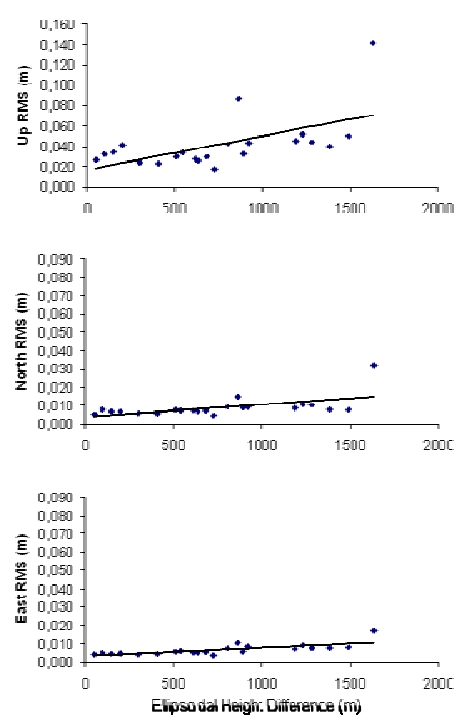

2-h
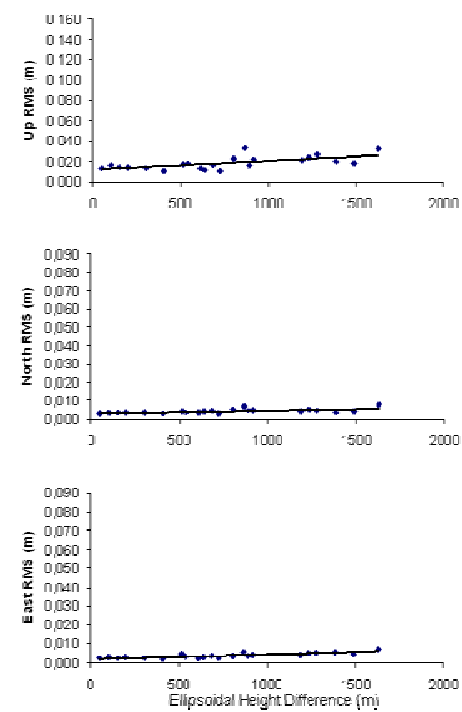

3-h
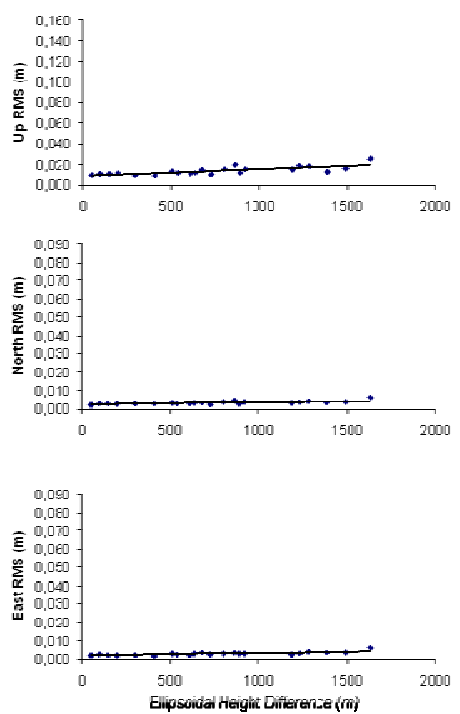

Fig. 2. Accuracy variation with respect to session length and ellipsoidal height difference

On the other hand, the positioning accuracy is less affected for horizontal components (n and e) since the effect is a factor of 2 or so smaller than that of the vertical component. Correlation coefficients for the range 1-3 h vary between 0.6 and 0.8 . Correlation coefficients for longer sessions for all the baseline components are presented in Figure 3. As seen from the figure, as observing session duration gets longer the correlation between ellipsoidal height difference and solution RMS decreases. Although the correlations for the horizontal components seem to be higher, the effect on the solutions is smaller as noted earlier (Figure 2).

TS 3H - Reliability of Positioning and Measurement Technology 
In Figure 2, 1-Sigma RMS errors are shown. For confidence levels of 95\% the effect could be quite serious (i.e. $\sim 4 \mathrm{~cm}$ for $1500 \mathrm{~m}$ height difference from $3 \mathrm{~h}$ sessions) in the presence of a large height difference for the vertical component up to sessions of $8 \mathrm{~h}$. Therefore for mountainous areas, we suggest observing session durations be extended up to $12 \mathrm{~h}$. On the other hand, for flat surfaces, no need to keep observing session duration longer than $3 \mathrm{~h}$. In the literature, we witness many engineering studies carried out in presence of large height differences use short GPS data accusation intervals, hence the effect is bigger on the vertical component for such studies (Brunner 2005, Lovse et al. 1995, Schon 2007)

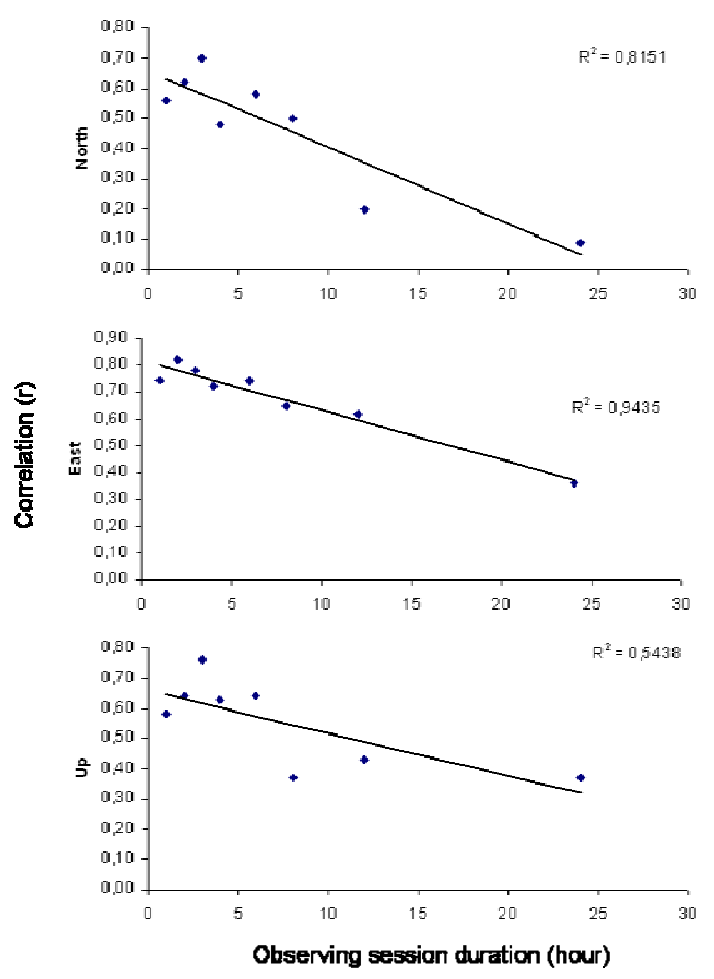

Fig. 3. As the session length grows the correlation between solution RMS and ellipsoidal height difference decreases

\section{MODELING HEIGHT DEPENDENT VARIATION}

Using the approach given in Eckl et al. (2001) we modelled the RMS variation with respect to inter-station height difference and observing session duration. Figure 4 illustrates the variation of RMS errors from all three GPS baseline components (namely north, east, and up) with respect to ellipsoidal height difference and observation window. Again note the scale difference for the vertical axis between the vertical and horizontal components.

We adopted the functional model developed by Eckl et al. (2001). According to this, the standard error in the north-south direction as a function of ellipsoidal height difference $\Delta h$ and observing session duration $T$ may be adequately represented by an equation of the form

TS 3H - Reliability of Positioning and Measurement Technology 


$$
S_{n}(\Delta h, T)=\left[a_{n} / T+b_{n} \Delta h^{2} / T+c_{n}+d_{n} \Delta h^{2}\right]^{0.5}
$$

where $a_{n}, b_{n}, c_{n}$, and $d_{n}$ are the constants to be estimated using Least Squares (LS) estimation. Equations of the same form were assumed to represent $S_{e}(\Delta h, T)$ and $S_{u}(\Delta h, T)$, the standard errors in the east-west direction and in the up direction respectively. Here $S_{n}, S_{e}$, and $S_{u}$ are expressed in $m m, \Delta h$ is expressed in $m$, and $T$ is expressed in hours. Reader might refer to Eckl et al. (2001) for the details of LS analysis. In Figure 4, the predicted accuracies using the significant coefficients developed in this study is given with the grey curve fitted to $6 \mathrm{~h}$ solutions.
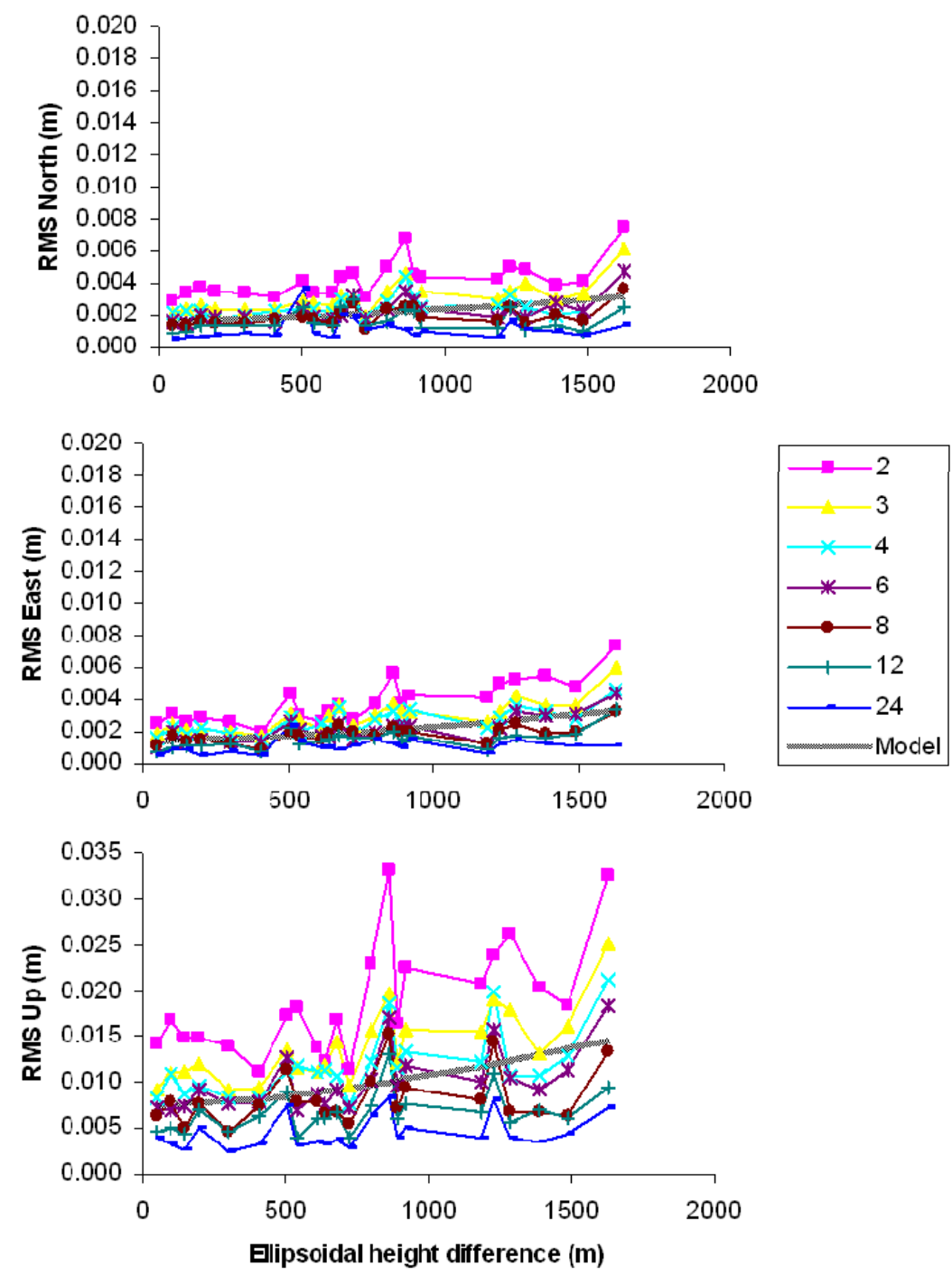

Fig. 4. Variation of RMS errors with respect to observing session duration and ellipsoidal height difference

TS 3H - Reliability of Positioning and Measurement Technology

D. Ugur Sanli and Fatih Kurumahmut

Accuracy of GPS Positioning in the Presence of Large Height Differences

Integrating Generations

FIG Working Week 2008

Stockholm, Sweden 14-19 June 2008 


\section{CONCLUSIONS}

In this study, we showed how large inter-station height difference affects the accuracy of GPS baseline components. The variation of positional RMS errors (i.e. for $n$, e, and $u$ ) with respect to observing session duration was also studied in detail. Empirical studies implemented here reveal that large station height differences bias GPS solutions even if the relative troposphere between baseline points is estimated. Especially land slide monitoring studies and volcano monitoring studies carried out in GPS campaigns (i.e. with short GPS sessions) would be affected much unless the effect of large height difference is taken into account. Previously, correction models using continuous GPS data were adopted in the elimination of large height difference error. This study shows that GPS survey planning in the office prior to field works gains importance for the engineering and geodetic studies using large height differences. It is also useful for GPS network optimisation and geoid determination studies. Furthermore, the effect of the large station height difference needs to be considered in modelling of GPS accuracies as an additional constraint.

\section{ACKNOWLEDGEMENTS}

We are grateful to NASA's Jet Propulsion Laboratory for providing GIPSY OASIS II software and for satellite orbit and clock solution files. We also thank to Scripps Orbit and Permanent Array Centre (SOPAC) researchers for opening their archives to scientific activities worldwide.

\section{REFERENCES}

Blewitt, G., 1993. Advances in Global Positioning System technology for geodynamics investigations. In Contributions of Space Geodesy to Geodynamics: Technology, Ed. by D.E. Smith and D.L. Turcotte, American Geophysical Union (Geodynamics Series Vol. 25), Washington DC. p. 195-213

Boehm, J., Niell, A., Tregoning, P. and Schuh, H., 2006. Global Mapping Function (GMF): A new empirical mapping function based on numerical weather model data. Geophysical Research Letters, 33: L07304, doi:10.1029/2005GL025546

Brunner, F.K., 2005. Bridge monitoring: external and internal sensing issues. In: Ou JP, Li H, Duan ZD (eds) Structural health monitoring and intelligent infrastructure. Balkema, pp 693-698

Eckl, M. C., Snay, R.A., Soler, T., Cline, M.W., Mader, G.L ., 2001. Accuracy of GPSderived relative positions as a function of inter-station distance and observing-session duration. Journal of Geodesy, 75: 633-640

Gurtner, W., Beutler, G., Botton, S., Rothacher, M., Geiger, A., Kahle, H.G., Schneider, D., Wiget, A., 1989. The use of the Global Positioning System in mountainous areas. Manuscripta Geodaetica, 14: 53-60

Kouba, J. (2005), Personal Communication

Lovse, J.W., Teskey, W.F., Lachapelle, G., Cannon, M.E., 1995. Dynamic deformation monitoring of tall structures using GPS technology. Journal of Surveying Engineering, 121(1):35-40

TS 3H - Reliability of Positioning and Measurement Technology

D. Ugur Sanli and Fatih Kurumahmut

Accuracy of GPS Positioning in the Presence of Large Height Differences

Integrating Generations

FIG Working Week 2008

Stockholm, Sweden 14-19 June 2008 
Niell, A.E., 1996. Global mapping functions for the atmosphere delay at radio wavelengths. Journal of Geophysical Research, 101 (B2): 3227-3246

Sanli, D. U., Akpınar, B., Erol, T., 2005. Assessing GPS Vertical Positioning Accuracy Using Various Troposphere Estimation Strategies. In: Advances in GPS Data Processing and Modelling for Geodynamics, COMET Meeting. UCL, London, 9-11 November, http://www-research.ge.ucl.ac.uk/COMET/

Sanli, D.U., 2006. Impact of large height differnce on GPS vertical positioning solutions, AGU 2006 Fall Meeting, San Francisco, CA, ABD, 11-15 Dec

Sanli, D. U. and Kurumahmut, F. 2007. Effect of Inter-station Height Difference on GPS Vertical Positioning Accuracy. IUGG 2007 General Assembly. Perugia-Italy, 2-13 July

Sanli, D. U. and Engin, C. 2007, Accuracy of GPS Positioning over Regional Scales. Survey Review, in press.

Schön, S., 2007. Affine distortion of small GPS networks with large height differences. GPS Solutions, 11: 107-117

Soler, T., Michalak, P., Weston, N. D., Snay, R. A., Foote, R. H., 2005. Accuracy of OPUS solutions for 1- to 4-h observing sessions. GPS Solutions, 10: 45-55

Zumberge, J. F., Heflin, M. B., Jefferson, D. C., Watkins, M. M., and Webb, F. H., 1997. Precise point positioning for the efficient and robust analysis of GPS data from large networks, Journal of Geophysical Research, 102: 5005-5017.

\section{BIOGRAPHICAL NOTES}

\section{Ugur Sanli}

$\mathrm{PhD}$ in the Newcastle University, UK. (1995-1999). Research Associate in Yildiz Technical University, Istanbul/Turkey (1989-1995). Assistant Professor in Yildiz Technical University, Istanbul/Turkey (1999-2006). Guest Member of Staff in the Newcastle University, UK (2003). Guest Lecturer in Yeditepe University, Istanbul/Turkey (2006). Assistant Professor in Kandilli Observatory and Earthquake Research Institute, Bogazici University, Istanbul/Turkey (2006 - ). Area of experience is mainly on Geodesy, GPS and Statistics, Publications are on monitoring sea levels using GPS, determining the accuracy of GPS positioning, using Robust Statistics to analyze geodetic data, monitoring sea levels using satellite altimetry. Member of Americal Geophysical Union, Turkish Chamber of Surveying Engineers, Union of Turkish National Geodesy and Geophysics.

\section{Fatih Kurumahmut}

BSc Degrees from Geodesy and Photogrammetry Engineering Department and Civil Engineering Department, Civil Engineering Faculty of Yildiz Technical University, Istanbul/Turkey (2003), MSc Student in Geomatics Program in the Science Institute of Yildiz Technical University, Istanbul/Turkey (2004 - ) 


\section{CONTACTS}

Assistant Professor, D. Ugur Sanli

Kandilli Observatory and Earthquake Research Institute, Bogazici University

34680 Cengelkoy

Istanbul

TURKEY

Tel. + 902165163364

Fax + 902163320241

Email: ugur.sanli@boun.edu.tr

Web site: http://www.koeri.boun.edu.tr/jeodezi/sanli

Mr. Fatih Kurumahmut

Geomatics, Science Institute, Yildiz Technical University

34349 Yildiz

Istanbul

TURKEY

Tel. +902123832987

Fax. +90 02122596762

Web site: http://www.jfm.yildiz.edu.tr

TS 3H - Reliability of Positioning and Measurement Technology

D. Ugur Sanli and Fatih Kurumahmut

Accuracy of GPS Positioning in the Presence of Large Height Differences

Integrating Generations

FIG Working Week 2008

Stockholm, Sweden 14-19 June 2008 